\title{
DESENVOLVIMENTO E PROTOTIPAGEM DE JOGOS NÃO DIGITAIS EM UM CONTEXTO DE ENSINO E APRENDIZAGEM DE GAME DESIGN
}

\section{DEVELOPMENT AND PROTOTYPING OF NON-DIGITAL GAMES IN A CONTEXT OF TEACHING AND LEARNING GAME DESIGN}

\author{
Eduardo Napoleão ${ }^{1}$, M.Sc \\ Marília Kimie H. T. Yonekawa², Bel. \\ Gilson Braviano ${ }^{3}$, Dr. \\ Guilherme Sauthier ${ }^{4}$, Esp. \\ Marília Matos Gonçalves ${ }^{5}$,Dra.
}

(1) Universidade do Vale do Itajaí - UNIVALI

e-mail: eduardonapoleao@univali.br

(2) Universidade do Vale do Itajaí - UNIVALI

e-mail: mariliayonekawa@gmail.com

(3) Universidade Federal de Santa Catarina - UFSC

e-mail: gilson@cce.ufsc.br

(4) Universidade do Vale do Itajaí - UNIVALI

e-mail:guisauthier@gmail.com

(5) Universidade Federal de Santa Catarina - UFSC

e-mail: marilinhamt@gmail.com 


\section{$16^{\circ}$ \\ ERGODESIGN USIHC CINAHPA}

$16^{\circ}$ Ergodesign - Congresso Internacional de Ergonomia e Usabilidade de Interfaces Humano Tecnológica: Produto, Informações Ambientes Construídos e Transporte

$16^{\circ}$ USIHC - Congresso Internacional de Ergonomia e Usabilidade de Interfaces Humano Computador

CINAHPA | 2017 - Congresso Internacional de Ambientes Hipermídia para Aprendizagem.

\section{Game Design, Processo, Prototipagem}

O presente trabalho investiga o uso de jogos não-digitais como mídia de aprendizado acadêmico focando o desenvolvimento de conceitos e aprendizagem de processos de construção e design de jogos em alunos de fases iniciais do curso de graduação em Design de Jogos e Entretenimento Digital da Universidade do Vale do Itajaí (Univali). Os projetos propostos foram realizados com o objetivo de apresentar para os alunos, através de atividades projetuais, a importância da organização de um projeto de design em etapas lógicas, assim como estimular a prototipagem no desenvolvimento de jogos. A partir da aplicação prática e do processo de desenvolvimentos dos projetos de jogos com foco em design buscou-se desenvolver jogos originais, de acordo com critérios limitantes, e avaliá-los a partir do uso dos protótipos.

\section{Game Design, Process, Prototyping}

The present work investigates the use of non-digital games as academic learning media focusing on the development of concepts and learning of the processes of construction and game design in students of the initial stages of the graduation course in Games Design and Digital Entertainment, University of Valley of Itajai (Univali). The proposed projects were carried out with the objective of presenting to students, through project activities, the importance of organizing a design project in logical steps, as well as stimulating prototyping in game development. From the practical application and the process of development of games projects with a focus on design, we tried to develop original games, according to limiting criteria, and to evaluate them from the use of the prototypes.

\section{Introdução}

O jogo e o ato de jogar são elementos presentes na cultura humana desde momentos anteriores ao advento e popularização dos jogos digitais. Johan Huizinga (1971) defende inclusive que o jogo é uma atividade central em determinadas sociedades, nas quais podemos ser caracterizados como Homo Ludens.

Dentre as várias categorias de jogos, existem aqueles que não são experenciados a partir de mídias digitais. Alguns desses jogos não digitais são conhecidos como boardgames, cardgames e também tabletop games (SELINKER, 2011). Popularmente, podem também ser chamados de jogos de tabuleiro. Os jogos de tabuleiros foram inseridos na sociedade na antiguidade e possuem uma essência parecida com os jogos em geral, de promover o entretenimento. Os boardgames podem ser vistos como "um sistema no qual os jogadores se envolvem em um conflito artificial, definido por regras, que implica um resultado quantificável", como definem Salen e Zimmerman (2004). Para os autores, a imersão dos players dentro de um jogo de tabuleiro pode ocorrer através de elementos como: comportamento individual, manipulação de espaço e objetos. Logo, quando os jogadores seguem as regras de um jogo e fazem uso do sistema através do próprio jogo, eles estão interpretando a gameplay (ou jogabilidade) que o game designer definiu. Em relação a proposta apresentada e descrita no presente artigo, esses jogos são utilizados como mediadores do processo de aprendizagem de alunos de fases iniciais do curso de Design de Jogos e Entretenimento Digital da Universidade do Vale do Itajaí (Univali). Através deles, é possível apresentar aos alunos conceitos sobre métodos e processos de design e também especificamente de design de jogos, além do contato sensorial e prototipagem de peças, desenvolvimento e organização de regras, a relação do produto entre os desenvolvedores e entre os jogadores, assim como dos jogadores e dos desenvolvedores, cultura de jogos, fundamentos da linguagem do design, questões artísticas, desenvolvimento de histórias, roteiros e personagens, fundamentos de estratégias de marketing com o objetivo de financiar os jogos 


\section{$16^{\circ}$ \\ ERGODESIGN USIHC CINAHPA}

entre os alunos, desenvolvimento intelectual, tomada de decisões, socialização, liberdade para testes e erros dentro do processo de design e considerando a prototipagem como elemento fundamental, iterativo e não linear do processo, características sensoriais, experiência de usuário, dentre outros. Outras fundamentações para o uso de jogos não digitais como parte desse processo estão relacionadas ao faturamento de mercado da empresa brasileira de jogos de tabuleiro

Galápagos, a qual esperava obter uma renda de 15 milhões de reais em 2015 (RAPHAEL, 2015). Além disso, prototipagem rápida e iteração são práticas utilizadas pelo autor Eric Zimmerman (2013) e aplicadas como forma de ensinar para os alunos do curso de game design da New York University os processos de design focados no desenvolvimento de jogos.

O processo proposto para a atividade em questão é dividido em três etapas principais, nas quais os alunos criam diferentes projetos de jogos não digitais. Para o artigo em questão, considerou-se a produção de um jogo original, baseado em determinados critérios limitantes.

\section{Conceitos de Design e de Game Design}

Para entender o processo de criação, necessita-se definir o que é design e também o que seria o game design. Para Wheeler (2012), design é, antes de tudo, um processo iterativo que busca o equilíbrio entre as questões formais e as questões

significativas. A definição da autora admite a não linearidade do processo de design, assim como a existência de uma linguagem binária. No mesmo sentido, Noble (2013) descreve a existência duas linguagens fundamentais no design. A primeira a linguagem denotativa, relacionada com "o que um objeto é, e não aquilo que significa". Assim, aquilo que percebemos diretamente da forma caracteriza essa linguagem específica, também chamada de primária. Por outro lado, há uma segunda característica da linguagem, chamada de conotativa ou secundária, que diz respeito às sensações, sentimentos e lembranças relacionados com nossa percepção das coisas. Assim, pode-se afirmar que a linguagem do design é construída a partir dessas duas características, dentro de um processo iterativo e não-linear. $16^{\circ}$ Ergodesign - Congresso Internacional de Ergonomia e Usabilidade de Interfaces Humano Tecnológica: Produto, Informações Ambientes Construídos e Transporte

$16^{\circ}$ USIHC - Congresso Internacional de Ergonomia e Usabilidade de Interfaces Humano Computador

CINAHPA | 2017 - Congresso Internacional de Ambientes Hipermídia para Aprendizagem.
Além das definições gerais do universo do design é importante apresentar definições específicas da cultura do design de jogos. Schuytema (2008) apresenta uma definição para jogos digitais ou eletrônicos:

Um game é uma atividade lúdica composta por uma série de ações e decisões, limitado por regras e pelo universo do game, que resultam em uma condição final. As regras e o universo do game são apresentados por meios eletrônicos e controladas por um programa digital. As regras e o universo do game existem para proporcionar uma estrutura e um contexto para as ações de um jogador. As regras também existem para criar situações interessantes com o objetivo de desafiar e se contrapor ao jogador. As ações do jogador, suas decisões, escolhas e oportunidades, na verdade, sua jornada, tudo isso compõe a "alma do game". A riqueza do contexto, o desafio, a emoção e a diversão da jornada de um jogador, e não simplesmente a obtenção da condição final, é que determinam o sucesso do game.

A partir dessa definição, o autor elenca vários fatores fundamentais para a existência de um jogo, sendo que algumas delas (como a atividade lúdica, a existência de regras, uma condição final, uma estrutura e um contexto para a execução de ações) podem ser consideradas como extensivas às características básicas de jogos não digitais. Rogers (2014) apresenta uma visão mais simples do termo. Para o autor, "um game é uma atividade que requer a existência de pelo menos um jogador, regras e uma condição de vitória ou derrota". Assim, a palavra game pode tanto ser referência para o objeto "jogo" como pode significar o ato de jogar, diversão e entretenimento. O game designer é quem pratica a ação de elaborar, adaptar, projetar e criar atendendo as necessidades propostas e respeitando questões estéticas, ergonômicas e visuais. Portanto, pode-se dizer que o designer de jogos é o projetista do jogo, aquele que projeta a jogabilidade (gameplay), concebe e elabora regras e estruturas que resultam em uma experiência para o jogador ou os jogadores. Na visão de Salen e Zimmerman (2004), um designer de jogos não é necessariamente um programador, um designer gráfico ou gerente de projeto, embora às vezes também possa desempenhar essas funções na criação de um jogo.

Realização:




\section{$16^{\circ}$ \\ ERGODESIGN USIHC CINAHPA}

\section{Processo de desenvolvimento do Jogo}

O processo de design de um jogo não digital aplicado na disciplina proposta possui referências da cultura do design gráfico e do design de jogos, sendo proposta a partir de estudos, metodologias, práticas e processos de design de autores como Brown (2010), Munari (2008), Salen e Zimmerman (2004) e Schell (2011). Para a proposta do desenvolvimento dos jogos, são definidas três etapas gerais, sendo (1) pesquisa, na qual o aluno recebe um tema proposto para o desenvolvimento do jogo; (2) geração de ideias, na qual as ideias são concebidas, geradas e organizadas de acordo com limitações específicas; e (3) prototipação.

Considera-se a existência de outras etapas inseridas no contexto de cada uma das etapas gerais. $\mathrm{O}$ processo é iterativo (WHELLER, 2012), pois essa é uma característica comum às duas áreas gerais pesquisadas.

Para Selinker (2011), o desenvolvimento de um jogo geralmente inicia com um tema ou uma mecânica. Nesse sentido, e considerando as etapas de prototipagem e o processo iterativo de design, uma característica deve ser desenvolvida em função de suportar a experiência objetivada pela outra. A figura 01 apresenta um esquema demonstrando o processo de desenvolvimento proposto pelo autor em questão.

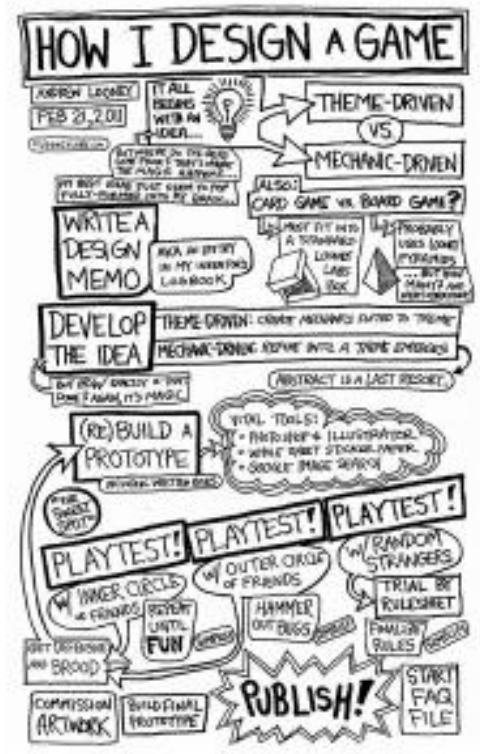

$16^{\circ}$ Ergodesign - Congresso Internacional de Ergonomia e Usabilidade de Interfaces Humano Tecnológica: Produto, Informações Ambientes Construídos e Transporte

$16^{\circ}$ USIHC - Congresso Internacional de Ergonomia e Usabilidade de Interfaces Humano Computador

CINAHPA | 2017 - Congresso Internacional de Ambientes Hipermídia para Aprendizagem.
Assim, num primeiro momento, os alunos são apresentados a temas limitadores que devem ser interpretados de acordo com as pesquisas de cada um dos grupos de game designers. Os fatores limitantes geralmente são temas gerais como racismo, mobilidade, sustentabilidade, dentre outros, e arquétipos como herói, fora-da-lei e governante. Nessa etapa, os alunos devem desenvolver suas primeiras pesquisas e apresentar em sala de aula o resultado delas. Selinker (2011) afirma que é importante manter um diário com as características do desenvolvimento do jogo anotadas. Essas regras podem ajudar a desenvolver novas mecânicas e, consequentemente, o manual de regras do jogo. A figura 02 apresenta o diário de pesquisa e desenvolvimento de jogo de uma das alunas, que é usado como uma das técnicas para se organizar as pesquisas iniciais do jogo.

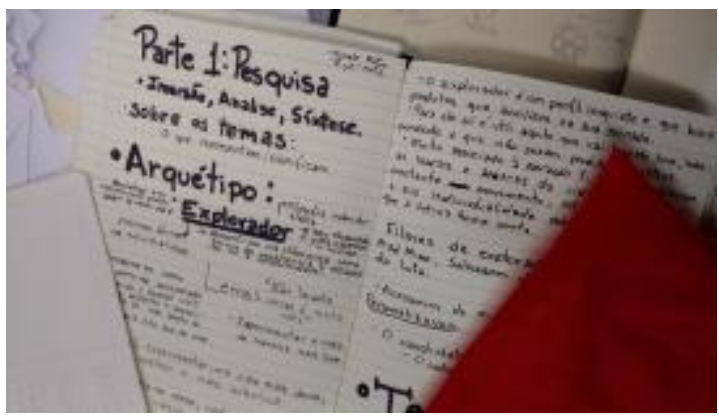

Figura 02 - Diário de desenvolvimento de jogo Fonte: Autor (2017)

Outra técnica utilizada na primeira etapa é a imersão em jogos já existentes, na qual os alunos jogam, analisam e discutem as regras, artes, histórias e mecânicas de jogos já produzidos. Na figura 03 , os alunos jogam e discutem as características do jogo de tabuleiro Ticket to Ride. 


\section{$16^{\circ}$ ERGODESIGN USIHC CINAHPA}

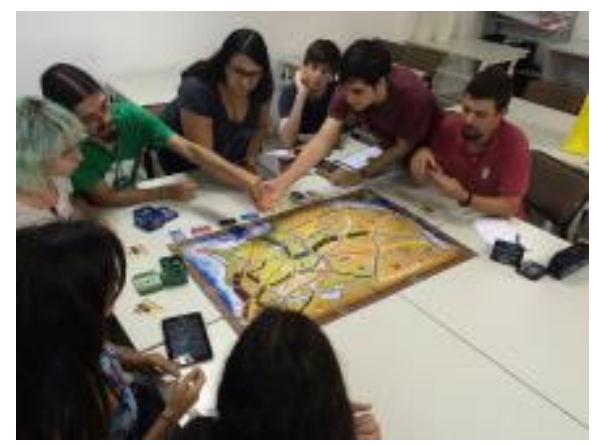

Figura 03 - Imersão no jogo Ticket to Ride Fonte: Autor (2017)

Após a apresentação e validação das mesmas, os primeiros conceitos são gerados e, assim que possível, prototipados em torno de estruturas nas quais todos possam jogar, testar e avaliar seus próprios produtos em sala de aula. A figura 04, imagens A e B, mostra o desenvolvimento dos primeiros conceitos na etapa de conceituação e preparação para a prototipagem.

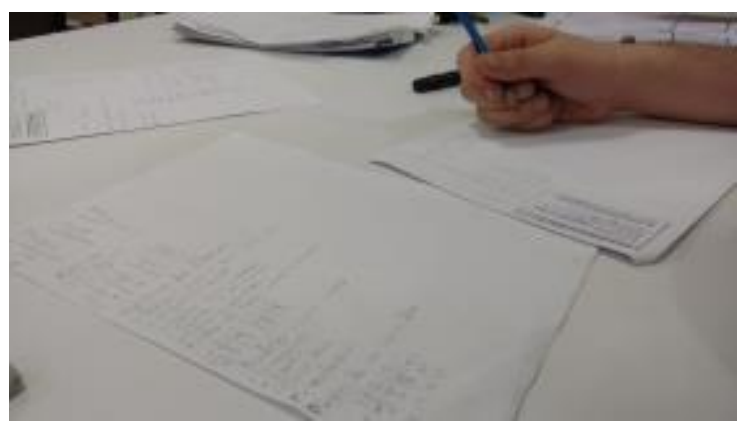

Figura 04 - (A) Etapa de conceituação Fonte: Autor (2017)

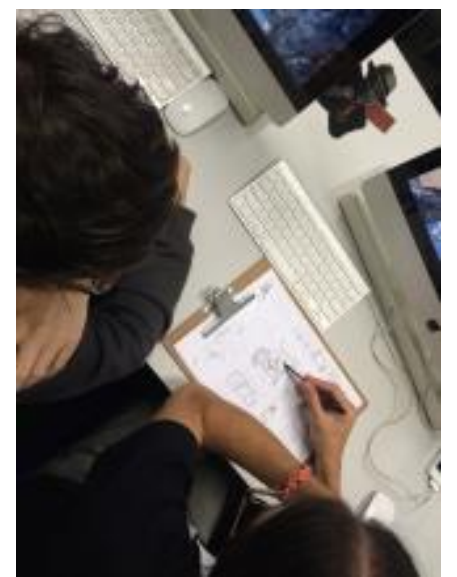

Figura 04 - (B) Etapa de conceituação Fonte: Autor (2017) $16^{\circ}$ Ergodesign - Congresso Internacional de Ergonomia e Usabilidade de Interfaces Humano Tecnológica: Produto, Informações Ambientes Construídos e Transporte

$16^{\circ}$ USIHC - Congresso Internacional de Ergonomia e Usabilidade de Interfaces Humano Computador

CINAHPA | 2017 - Congresso Internacional de Ambientes Hipermídia para Aprendizagem.

Para conceituar o jogo, precisa-se entender como os jogos funcionam e quais suas essências. Para isso, deve-se responder a uma série de questionamentos sobre o jogo, tal como Dunniway e Novak (2008) propõem na tabela 01. A ideia principal do jogo nasce na etapa de conceituação, na qual ferramentas de geração de ideias são utilizadas como forma de criar e gerar possíveis caminhos para o desenvolvimento do primeiro protótipo do jogo. Essa etapa serve como uma ponte entre a primeira etapa, na qual a pesquisa é executada, e a terceira, de prototipação. Assim, a pesquisa é organizada e estruturada em torno de uma ideia, que será prototipada de acordo com os princípios dos jogos, considerando questões como o enredo e o universo do jogo, a jornada e as ações lógicas dos jogadores, as mecânicas de jogo e também sua arte e aspectos como seu nome, marca, personagens e artes conceituais.

\begin{tabular}{|l|l|l|}
\hline Questionamentos & Descrição & $\begin{array}{l}\text { Exemplo: jogo } \\
\text { Xadrez }\end{array}$ \\
\hline $\begin{array}{l}\text { Qual a essência } \\
\text { do jogo? }\end{array}$ & $\begin{array}{l}\text { Idéia ou } \\
\text { característica } \\
\text { central. }\end{array}$ & $\begin{array}{l}\text { Conquistar o } \\
\text { "Rei" do } \\
\text { adversário. }\end{array}$ \\
\hline $\begin{array}{l}\text { Quem é o } \\
\text { jogador? }\end{array}$ & $\begin{array}{l}\text { Perfil do seu } \\
\text { público-alvo. }\end{array}$ & $\begin{array}{l}\text { Pessoas } \\
\text { interessadas em } \\
\text { desenvolver um } \\
\text { raciocínio mais } \\
\text { eficiente, } \\
\text { normalmente } \\
\text { acima de 5 anos. }\end{array}$ \\
\hline $\begin{array}{l}\text { O que o jogador } \\
\text { faz? }\end{array}$ & $\begin{array}{l}\text { Qual a } \\
\text { mecânica } \\
\text { principal para } \\
\text { atingir o } \\
\text { objetivo. }\end{array}$ & $\begin{array}{l}\text { Movimentando as } \\
\text { peças através de } \\
\text { caminhos e } \\
\text { padrões pré- } \\
\text { definidos }\end{array}$ \\
\hline $\begin{array}{l}\text { Como o jogador } \\
\text { faz? }\end{array}$ & $\begin{array}{l}\text { Como o } \\
\text { jogador atinge } \\
\text { esse objetivo. }\end{array}$ & $\begin{array}{l}\text { Quando o "Rei" } \\
\text { inimigo está } \\
\text { cercado }\end{array}$ \\
\hline faz? o jogador & $\begin{array}{l}\text { Como o } \\
\text { jogador utiliza o } \\
\text { espaço do } \\
\text { tabuleiro para } \\
\text { fazer } \\
\text { determinada } \\
\text { jogada. }\end{array}$ & $\begin{array}{l}\text { Em um tabuleiro } \\
\text { de 64 casas (32 } \\
\text { brancas e 32 } \\
\text { negras). }\end{array}$ \\
\hline O jogador & Os jogadores \\
\hline
\end{tabular}




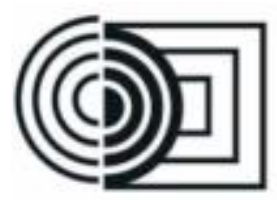

$16^{\circ}$ Ergodesign - Congresso Internacional de Ergonomia e Usabilidade de Interfaces Humano Tecnológica: Produto, Informações Ambientes Construídos e Transporte

$16^{\circ}$ USIHC - Congresso Internacional de Ergonomia e Usabilidade de Interfaces Humano Computador

CINAHPA | 2017 - Congresso Internacional de Ambientes Hipermídia para Aprendizagem.

\begin{tabular}{|l|l|l|}
\hline jogador faz? & $\begin{array}{l}\text { utiliza qual } \\
\text { artifício } \\
\text { (objetos e } \\
\text { interações } \\
\text { audio-visuais) } \\
\text { para chegar no } \\
\text { objetivo. }\end{array}$ & $\begin{array}{l}\text { dispõem de 32 } \\
\text { peças (16 para } \\
\text { cada jogador): 1 } \\
\text { Rei, 1 Rainha, 2 } \\
\text { Bispos, 2 Torres, } \\
\text { 2 Cavalos e 8 } \\
\text { Peões. }\end{array}$ \\
\hline $\begin{array}{l}\text { Com quem o } \\
\text { jogador faz? }\end{array}$ & $\begin{array}{l}\text { Ele joga } \\
\text { sozinho, com } \\
\text { outras } \\
\text { pessoas, } \\
\text { contra ou a } \\
\text { favor do jogo? }\end{array}$ & $\begin{array}{l}\text { Os jogos } \\
\text { envolvem 2 } \\
\text { pessoas, um } \\
\text { contra o outro. }\end{array}$ \\
\hline $\begin{array}{l}\text { Por que o } \\
\text { jogador faz? }\end{array}$ & $\begin{array}{l}\text { Qual o objetivo } \\
\text { de usar esses } \\
\text { artifícios? }\end{array}$ & $\begin{array}{l}\text { Para executar } \\
\text { uma estratégia a } \\
\text { fim de diminuir as } \\
\text { "defesas" da peça } \\
\text { principal, o "Rei". }\end{array}$ \\
\hline $\begin{array}{l}\text { Quais } \\
\text { características do } \\
\text { jogo se } \\
\text { destacam? }\end{array}$ & -------- & $\begin{array}{l}\text { As mecânicas } \\
\text { adotadas para } \\
\text { cada peça, a } \\
\text { diversidade de } \\
\text { estratégias }\end{array}$ \\
\hline
\end{tabular}

Tabela 01 - Questionamentos sobre o jogo Fonte: Dunniway e Novak (2008)

Ao definir cada tópico, o game designer deve desenvolver as mecânicas que vai utilizar e vinculá-las com as regras, de acordo com o tema proposto e as condições limitadoras. Após isso, inicia-se a terceira etapa do processo que deve-se ao desenvolvimento de um jogo a partir da prototipação das ideias propostas, seguida de validações constantes de acordo com as condições do processo iterativo de design. A figura 05 , imagens A, B e C, mostra algumas imagens de protótipos desenvolvidos pelos game designers durante a disciplina proposta.

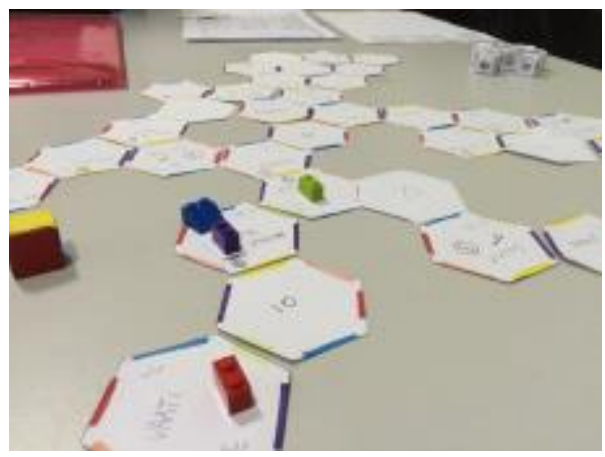

Figura 05 - (A) Protótipos de jogos não digitais Fonte: Autor (2017)

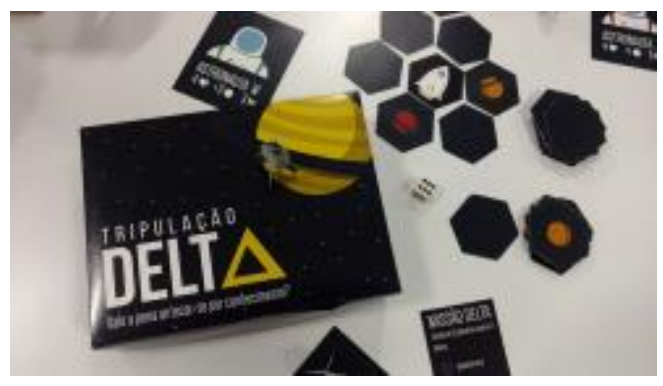

Figura 05 - (B) Protótipos de jogos não digitais Fonte: Autor (2017)

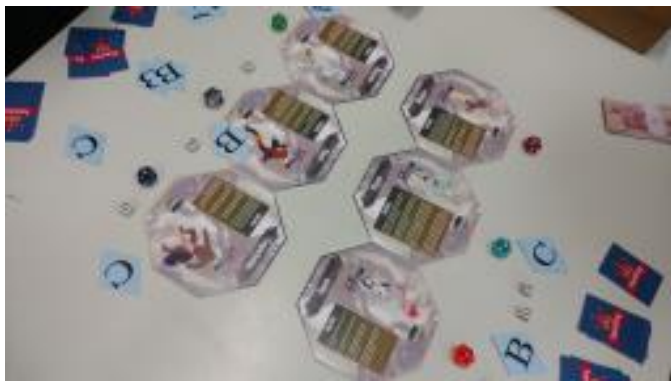

Figura $05-(\mathrm{C})$ Protótipos de jogos não digitais Fonte: Autor (2017)

Como forma de avaliar os resultados obtidos na etapa de prototipagem, considera-se as diferentes realidades avaliativas de um jogo. Para Calleja (2011), é importante distinguir o jogo enquanto um objeto e o jogo enquanto um processo. Para o autor, o boardgame Catan (desenvolvido por Teuber em 1995) é tanto um conjunto de materiais, objetos e regras quanto uma atividade construída a partir do uso desses elementos. Para o autor, as regras são passíveis de interpretação de acordo com os distintos grupos de jogadores e suas distintas culturas e contextos sociais. Assim, grupos distintos poderiam questionar a forma visual do jogo, disposto em peças hexagonais, ou mesmo as cores e formatos das ilustrações e cartas, e suas distintas interpretações poderiam afetar o modo como o jogo é experienciado, afetando consequentemente seu resultado final.

A prototipagem de um jogo possibilita uma rápida verificação das possibilidades de acertos e erros, junto com possíveis trocas de mecânicas e
Realização:

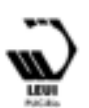




\section{$16^{\circ}$ \\ ERGODESIGN USIHC CINAHPA}

dinâmicas do tabuleiro. Segundo Paavilainen (2009), “ podemos ver que um protótipo é uma amostra do produto final rapidamente desenvolvida que demonstra algumas ou todas as suas capacidades funcionais". De acordo com Sato (2010) a prototipagem de jogos é relevante para o processo pois facilita a interação e a comunicação de ideias entre os integrantes de uma equipe, possibilita o teste de ideias e dos conceitos, assim como de sua viabilidade de acordo com as regras e mecânicas do jogo, facilita o entendimento das questões físicas e espaciais, faz com que os pontos de interação entre jogadores possam ser testados, facilita o balanceamento e equilíbrio dos sistemas do jogo, oferece formas rápidas de feedback entre os jogadores e os game designers, além de ser rápida e barata.

Como forma de validar o protótipo, os alunos são convidados a apresentá-lo em uma data específica, variável de acordo com o prazo do projeto. Nessa data, os próprios alunos avaliam os jogos de todos, em conjunto com o professor da disciplina, através de uma simulação de financiamento coletivo. Assim, todos devem simular um determinado investimento monetário em cada um dos jogos produzidos, a partir de valores iguais liberados para cada um dos alunos. Além disso, eles não são autorizados a investirem nos seus próprios jogos.

Como forma de estimular a identificação e experiência dos jogos, eles devem desenvolver embalagens e posters promocionais para o evento, de acordo com figura 06, imagens A, B e C.

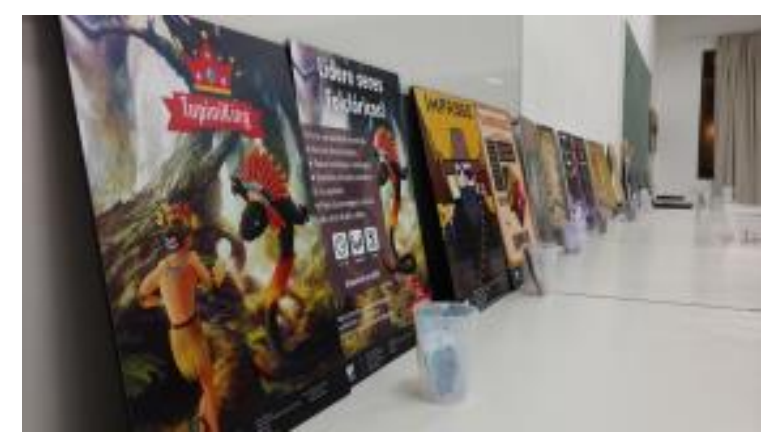

Figura 06 - (A) Apresentação dos protótipos de jogos Fonte: Autor (2017) $16^{\circ}$ Ergodesign - Congresso Internacional de Ergonomia e Usabilidade de Interfaces Humano Tecnológica: Produto, Informações Ambientes Construídos e Transporte

$16^{\circ}$ USIHC - Congresso Internacional de Ergonomia e Usabilidade de Interfaces Humano Computador

CINAHPA | 2017 - Congresso Internacional de Ambientes Hipermídia para Aprendizagem.

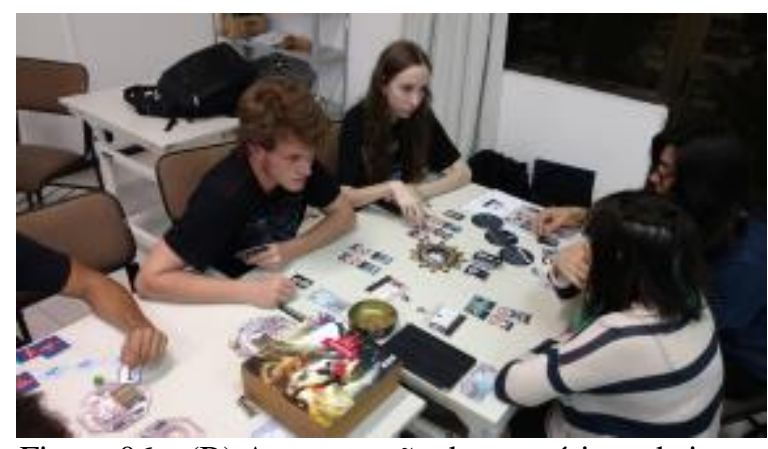

Figura 06 - (B) Apresentação dos protótipos de jogos Fonte: Autor (2017)

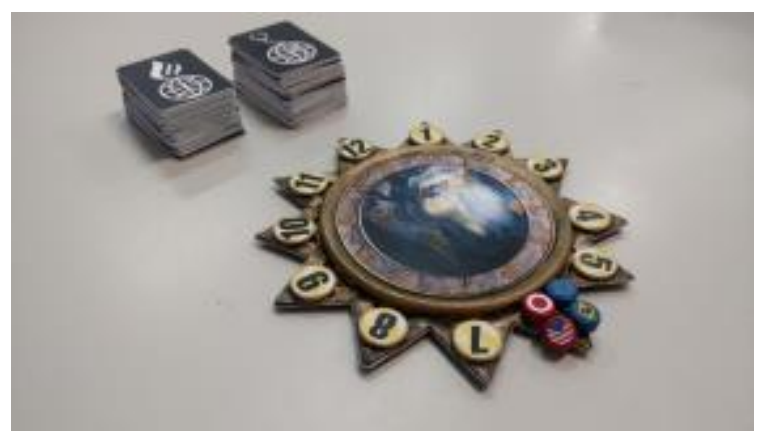

Figura 06 - (C) Apresentação dos protótipos de jogos Fonte: Autor (2017)

O objetivo dessa última etapa é estimular o uso, criação e aplicação de diferentes formas de contato entre os jogadores, seu público, o financiamento dos seus projetos e também a avaliação e conhecimento de outros projetos de jogos materializados a partir de um processo de design de jogos que considera a iteração e a prototipagem como partes essenciais da construção, teste e avaliação dos elementos significativos de um jogo. Para Selinker (2011), um jogo de sucesso deve ser jogado e testado inúmeras vezes, como forma de garantir o seu funcionamento adequado.

\section{Conclusão}

O game designer tem a responsabilidade de desenvolver o jogo e propor a experiência mais adequada possível. O processo de desenvolvimento do protótipo implica em constantes modificações, ajustes e alterações no projeto de um jogo, que devem ser avaliadas e corrigidas de acordo com os princípios do universo do design de jogos. Ao fim das etapas de pesquisa e ideação, a etapa do processo conhecida como prototipagem é iniciada, concluindo a criação e produção do produto em 


\section{$16^{\circ}$ \\ ERGODESIGN USIHC CINAHPA}

$16^{\circ}$ Ergodesign - Congresso Internacional de Ergonomia e Usabilidade de Interfaces Humano Tecnológica: Produto, Informações Ambientes Construídos e Transporte

$16^{\circ}$ USIHC - Congresso Internacional de Ergonomia e Usabilidade de Interfaces Humano Computador

CINAHPA | 2017 - Congresso Internacional de Ambientes Hipermídia para Aprendizagem. questão. Depois de avaliar a experiência de jogo, conceituá-lo, testar e prototipar, o game designer necessita produzir o modelo final do seu jogo, levando em consideração não somente a existência do jogo enquanto um processo, mas também enquanto um produto.

Para Calleja (2011) os jogos refletem os aspectos de uma determinada sociedade e cultura que os fizeram enquanto contribuem para o progresso da mesma. Além disso, é importante salientar que a experiência de jogo é diferente quando comparamos ambientes digitais e não-digitais, considerando principalmente os sentidos e as experiências provenientes das sensações dos mesmos.

Espera-se que, ao final da experiência de construção de um jogo não digital e da participação em diferentes etapas projetuais vivenciadas dentro de um processo de design ordenado, os alunos possam não somente entender a importância da prototipagem e da organização do projeto de um jogo, mas também que, considerando diferentes formas de financiamento do projeto, sintam-se encorajados a procurar formas de empreender o projeto no mercado de jogos. Além disso, que eles também busquem transformar as mecânicas, histórias, regras, arte, personagens e demais elementos do universo dos jogos, aqui materializados em um produto não digital, em produtos digitais, considerando alternativas hipermidiáticas ou transmidiáticas.

\section{BIBLIOGRAFIA}

CALLEJA, Gordon. In-Game: From Immersion to incorporation. Cambridge: MIT Press, 2011. DUNNIWAY, T.; NOVAK, J. Gameplay Mechanics. New York: Cengage Learning, 2008.

HUIZINGA, Johan. Homo ludens: o jogo como elemento da cultura. Editora da Universidade de S. Paulo, Editora Perspectiva, 1971.

MUNARI, Bruno. Das coisas nascem coisas. São Paulo: Martins Fontes, 2008.

NOBLE, Ian. Pesquisa Visual. Porto Alegre: Bookman, 2013.
PAAVILAINEN, J. Mobile Game Prototyping with the Wizard of $\mathrm{Oz}$. University of Tampere, 2009.

RAPHAEL, Pablo. (2015) Editora de jogos de tabuleiro espera faturar $\mathrm{R} \$ 15$ milhões em 2015. <online>. Disponível em: < https://jogos.uol.com.br/ultimasnoticias/2015/10/09/editora-deve-faturar-r-15-miem-2015-com-jogos-de-tabuleiro.htm>. Acesso em: 23 mar 2017.

ROGERS, Scott. Level Up! The guide to create video game design. United Kingdom: Wiley, 2014.

SALEN, K.; ZIMMERMAN, E. Rules of Play: Game Design Fundamentals. Massachusetts: MIT Press, 2004.

SATO, A. K. O. Game Design e Prototipagem: conceitos e aplicações ao longo do processo projetual. In: SBGames, São Paulo, 2010.

SELINKER, Mike. The Kobold Guide to Board Game Design. Kirkland: Open Design, 2011.

SCHELL, Jesse. The Art of Game Design: a book of lenses. Rio de Janeiro: Elsevier, 2011.

SCHUYTEMA, Paul. Design de games: uma abordagem prática. São Paulo: Cengage Learning, 2008.

WHEELER, Alina. Design de Identidade da Marca. Porto Alegre; Bookman, 2012.

ZIMMERMAN, Eric. (2013). How I Teach Game Design: Lesson 1, the Game Design Process. <online> . Disponível em:

$<$ http://www.gamasutra.com/blogs/EricZimmerma n/20131019/202710/How_I_Teach_Game_Design _Lesson_1_The_Game_Design_Process.php>. Acesso em: 23 mar 2017

Realização:

